Jean-Philippe Bonardi* and Santiago Urbiztondo

\title{
Asset freezing, corporate political resources and the Tullock paradox
}

\begin{abstract}
In 1967, Gordon Tullock asked why firms do not spend more on campaign contributions, despite the large rents that could be generated from political activities. We suggest in this paper that part of the puzzle could come from the fact that one important type of political activity has been neglected by the literature which focuses on campaign contributions or political connections. We call this neglected activity "asset freezing”: situations in which firms delay lay-offs or invest in specific technologies to support local politicians' re-election objectives. In doing so, firms bear a potentially significant cost as they do not use a portion of their economic assets in the most efficient or productive way. The purpose of this paper is to provide a first theoretical exploration of this phenomenon. Building on the literature on corporate political resources, we argue that a firm's economic assets can be evaluated based on their degree of "political freezability," which depends on the flexibility of their use and on their value for policy-makers. We then develop a simple model in which financial contributions and freezing assets are alternative options for a firm willing to lawfully influence public policy-making, and derive some of our initial hypotheses more formally.
\end{abstract}

*Corresponding author: Jean-Philippe Bonardi, Faculty of Business and Economics (HEC), University of Lausanne, Switzerland, e-mail: jean-philippe.bonardi@unil.ch

Santiago Urbiztondo: Fundación de Investigaciones Económicas Latinoamericanas (FIEL), Argentina

\section{Introduction}

In a famous piece written over 40 years ago, Gordon Tullock raised the following question: If the value of public policies can be high for many firms, why is there so little money in US politics? (Tullock 1967, 1972). This question remains known today as the "Tullock paradox" and has not been completely resolved by the economics, political science or management literatures (Ansolabehere, de Figueiredo, and Snyder 2003; Bonardi 2008, 2011). In spite of the billions of dollars of public expenditure and regulatory costs imposed on firms in the US, campaign contributions remain relatively low. Milyo, Primo, and Groseclose (2000), for instance, studied 15 large corporations in 1998. The firms in their sample gave $\$ 1611$ million to charities and just \$16 million to political campaigns. 
Candidates and party committees raised nearly $\$ 3$ billion during the 1999-2000 election cycle. ${ }^{1}$ However, only about $\$ 380$ million of those $\$ 3$ billion came directly from corporations. In addition, only $60 \%$ of the Fortune 500 companies have Public Action Committees (PACs), a number that should probably be considered as surprisingly low if political activities are truly a superior way to acquire regulatory rents.

A traditional treatment of the Tullock paradox is developed around the idea of rent dissipation, according to which political competition among firms would push these firms to use as much resources as possible to get the rent related to a public policy decision, in which case most of the value of the rent would be dissipated in the form of resources used up in the competition for that rent (DariMattiacci and Parisi 2005). However, empirical studies of the phenomenon have not backed up that proposition. Hazlett and Michaels (1993) estimate that, in the FCC cellular telephone bandwidth lotteries, approximately $38 \%$ of the rents were dissipated by the expenses associated with the preparation of applications - a significant proportion, certainly, but far from full dissipation. Similarly, consider the case of sugar producers highlighted by Stratmann (1991), in which a " $\$ 3000$ sugar PAC contribution maps into a yes vote with almost certainty." Stratmann argues that without sugar industry contributions, the final vote on the sugar amendment to the 1985 agriculture bill would have been 203-210, effectively ending the sugar subsidy, but contributions helped the subsidy to survive: the final vote was 267-146. A US General Accounting Office (1993) study values the annual transfer from consumers to sugar producers and processors at $\$ 1.1$ billion a year from 1989 to 1991. In other words, $\$ 192,000$ in contributions in 1985 bought more than $\$ 5$ billion for the industry over a 5-year period (Ansolabehere, Snyder, and Tripathi 2002), very far from dissipating rents.

So why do not firms invest more in political activities? In this paper, we argue that part of the paradox can be explained by the fact that some influential and costly political activities that firms adopt to impact public-policy decisions have not been taken into account in previous literature. To make this argument, we build on the Resource-Based View of the firm (Barney 1991) according to which there is heterogeneity among firms based on a set of resources and capabilities that are specific to each firm and which other firms cannot easily acquire, imitate or replicate. Several scholars have already applied the Resource-Based View of the firm to the domain of corporate political activities (Dahan 2005a; Oliver and Holzinger 2008; Holburn and Zelner 2010; Lawton and Rajwani 2011), and have

1 These numbers and many other interesting ones can be found in Ansolabehere, de Figueiredo, and Snyder (2003). 
attempted to identify the types of resources and capabilities that might be relevant in that context. Questions remain, however, about what corporate political resources really provide a competitive edge to certain firms, and why firms cannot acquire the political capabilities they need by hiring lobbyists or contracting with lobbying firms (Bonardi 2011). In this paper, we argue that firms can create specific political resources through their existing economic assets.

More specifically, we put the focus on a type of activity that we call "asset freezing" and that only firms - in contrast to other interest groups - can develop. We define asset freezing as a business action whereby the firm sacrifices profits in a way that is politically beneficial to an incumbent government. This type of political activity can include a broad range of practices, such as delaying lay-offs (Bertrand et al., 2006), anticipating increased employment, adopting "politically friendly" technologies, acquiring inputs from suppliers at higher than market prices, etc. ${ }^{2}$ Three situations might fall into the boundaries of what we call asset freezing here. First, a situation in which a firm plans to invest in a project for economic reasons, but over-invests for political reasons. Second, a situation in which a firm invests in a project whereas it would not have done so if politics was not a factor. Third, a situation in which a firm is considering downsizing or shutting down a unit or facility, but delays it for political reasons. In all three cases, the firm freezes economic assets in order to increase its bargaining power vis-à-vis policy-makers and make its lobbying more effective.

One enlightening example of asset freezing (non-monetary campaign contribution) recently occurred in Argentina and was uncovered by Wikileaks (as published by Diario El País of Spain and reproduced by local newspapers in Argentina). Prior to the 2007 presidential election, the incumbent government (headed by president Néstor Kirchner) struck an agreement with local banks by which the latter would offer very cheap loans to the general public (in particular, to buy real estate) in order to favor the electoral chances of the incumbent's presidential candidate (Néstor Kirchner's wife Cristina Fernández). The astonishing revelations by Wikileaks, reproducing diplomatic reports produced by the US embassy in Buenos Aires, point out that the arrangement was not really supposed to be implemented beyond the very short run, as the government was particularly interested in the announcement of cheap loans prior to the election, not their

2 We assume that opposite actions such as anticipation of layoffs, overdependence on less competitive imports, etc., which would deteriorate the domestic environment and thus relatively favor entrants, are not feasible because they would be understood as sabotage against the country (and would entail both legal and/or enormous reputational risks) and because there are no institutional opportunities for such a type of negotiated contributions (as happens with government officials in office who regulate and regularly meet with managers of various firms). 
eventual completion afterwards. This episode, then, contains a crude and recent illustration that campaign contributions are not always monetary, and that the incumbent government running for reelection is in a better position to receive in-kind contributions. ${ }^{3}$

Compared to campaign contributions, asset freezing practices have three specific characteristics. First, from a competitive standpoint, they generate corporate political resources that are much more difficult to imitate. Campaign contributions are pure monetary investments and, as such, are easy to imitate for competitors. On the other hand, assets frozen will be more specific to one firm and can generate a competitive advantage as suggested by the Resource-Based View (Barney 1991).

Second, "asset freezing-based" resources benefit mainly political incumbents and can therefore only be used by firms that want to influence incumbent politicians. Asset freezing therefore differs from campaign contributions, which are monetary transfers made at a precise moment in time and which can be received both by political incumbents and new entrants. The reason for this is that the benefits of asset freezing are always attributed by voters to the government in function. If lay-offs are delayed by firms in one region in the context of an asset freezing strategy, the politicians who will benefit from it in the eyes of the public will be incumbent politicians. Whereas money (campaign financing) can help both political competitors to get elected, asset freezing will support only the efforts of the incumbent. ${ }^{4}$

Third, asset freezing practices carry specific types of costs. By freezing assets, at least in the short-term, firms accept to be less competitive than they could be. In other words, firms support an internal cost related to their productive activities, whereas campaign contributions are external to the firms' productive activities. The magnitude of this cost will vary depending on the type of sector the firms belong to and the types of assets considered for freezing. The more competitive or technologically dynamic the sector, the higher the internal cost associated with asset freezing. Similarly, the more flexible the asset, i.e., the lower the cost to increase or decrease investment related to the asset, the more we should observe asset freezing compared to other political means (such as campaign contributions).

In this paper, we provide a first exploration of asset freezing in several ways, with the objective of paving the way for future research on the topic. First, we

3 Source: http://www.ambito.com/noticia.asp?id=568184.

4 Note that we assume here that no credible promise or commitment can be made by firms or interest groups when they attempt to influence policy-makers. Both asset freezing and campaign contributions are to be made and consumed right away. 
offer a conceptual discussion of how a firm's economic assets, and which assets, might be frozen in order to create a corporate political resource. Second, in order to explore the trade-offs involved for a firm, we offer a stylized model in which a firm can use both campaign contributions and asset freezing to influence policymaking. Contributions can be provided to either an incumbent politician or a new entrant, who compete to be elected. Results of the model highlight when asset freezing will be chosen over campaign contributions, and explain why large firms are more likely to use this type of political instrument.

\section{Asset freezing and corporate political resources}

Several authors, looking at firms operating in regulated markets (Bonardi et al., 2006) or more generally attempting to influence public policies (Schuler 1996), argue that a critical aspect to consider is whether these firms possess specific political resources, i.e., a set of unique assets and skills that might allow these firms to participate in policy debates, face the rivalry of competing interest groups, and effectively shape policy decisions (Dean and Brown 1995; Hillman et al. 1999; Baron 2003; Hillman 2005; Faccio 2006). Similar to the Resource Based View of the firm (Barney 1991; Peteraf 1993), which holds that a firm's resources that are idiosyncratic and valuable may result in sustained competitive advantage, it has thus been argued that firms, in many cases, can also develop specific political resources with similar attributes (Keim and Baysinger 1988). This literature identifies corporate political resources of various kinds such as knowledge and expertise of political processes (Holburn and Zelner 2010), reputation and political capital (Yoffie and Bergenstein 1985), or stakeholder support (Rehbein and Schuler forthcoming). Dahan (2005b), however, suggests that corporate political resources are often composed of a bundle of resources, combining various aspects which might even include economic resources and capabilities. Our asset freezing approach follows a similar intuition. Corporate political resources do not only build on political attributes, but also on a firm's economic attributes, in that case in freezing some of its assets to acquire political influence.

Our asset freezing concept speaks to two different ideas previously developed in the literature. First, it offers a development of the idea that firms integrate their market and nonmarket strategies (Baron 1995), i.e., that economic and political activities should be complementary to each other in many industries in which public policies or regulations impact outcomes. Here, we push this idea further by suggesting that, at the basis of this integration, one could find common asset investments. 
Second, and relatedly, the asset freezing concept is in line with what Dahan (2005b) calls the "dual purpose" of assets: many assets have not only economic value for firms, but can also hold political value. What we suggest here, however, is that generating this value might require actions that are not always complementary with productivity enhancing behaviors for firms. In other words, the integration of market and nonmarket activities, in spite of the dual purpose of assets, might not always be without costs. The question remains, however, of which economic assets could be frozen and could help in the context of a firm's political strategy. In what follows, we develop a conceptual framework to address this question. Following Ghemawat and del Sol (1998), a firm's assets can be categorized based on whether they are flexible or not (horizontal axis), and whether they have political value or not (vertical axis). We define the flexibility of an asset as indicating how costly it is for this firm to increase or decrease its investment in the asset. This includes both barriers to entry and barriers to exit (as in the notion of irreversibility). In other words, we define a politically flexible asset as an asset that a firm can both easily invest in and in which it is less costly to disinvest. From that definition, for instance, a firm's workforce is an asset that is more flexible than an investment in a high technology plant.

The other dimension indicates how political valuable an asset might be. This obviously depends highly on the context, and on the preferences of policy-makers. With governments elected based on a program focused on reducing pollution, for instance, a project to invest in a green technology will constitute a very valuable political asset for a firm, and will increase this firm's bargaining chips with the government.

From there, assets that are the most attractive for firms to freeze are those that are both flexible and politically valuable. Figure 1 represents this typology, and provides examples of the different kinds of assets. In the top left quadrant, a firm's asset has the lowest freezability potential as it has low political value and low flexibility. An example of this would be an investment project in a R\&D laboratory in a foreign country. An R\&D lab is an asset that is not flexible - the exit cost is high once the investment is made - and, if made in a foreign country, this asset loses much of its political value for the home government of the company. Conversely, a workforce investment project in a region with high unemployment generates high freezability potential as it is both flexible - the firm can adjust how many people will be temporarily employed and then easily lay them off afterwards - and highly valuable politically if unemployment is a key political election issue in that region. Asset freezing in that case should provide strong political resources to the firm making the investment.

The two other quadrants represent mixed solutions. In the top right, the investment project has high political value but low flexibility, making it more of 


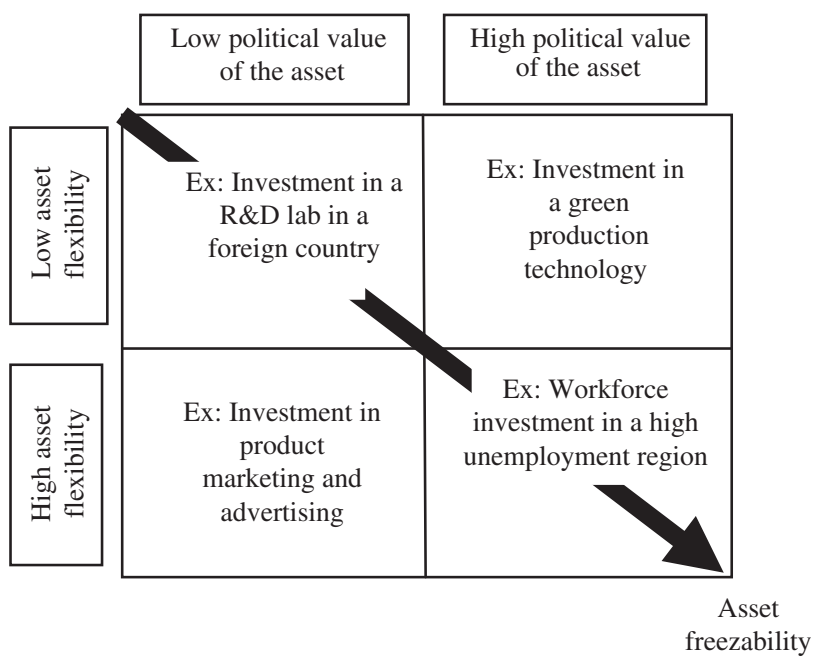

Figure 1 Determining asset freezability.

a long-term political commitment for a firm rather than asset freezing. An investment in a green production technology is an example of this. The asset involved would certainly create bargaining power with policy-makers upfront, but would not be very adjustable for the firm afterwards. In that case, this would be part of a long-term political investment strategy rather than asset freezing, and would likely jeopardize the firm's financial health on the long-run. In the bottom left, the investment project would be a flexible asset, but have low political value. A firm's investment in its marketing and advertising unit would constitute such an asset with limited freezability potential as it would be unlikely to be of much interest for policy-makers.

\section{A model of asset freezing and campaign contribution}

In what follows, we develop a formal model that accounts for the decision by a firm to trade-off campaign contributions and asset freezing. The purpose of this model is two-fold. First, we wish to explore in more details the trade-offs between asset freezing and another kind of political resource, in that case campaign contribution. Second, and despite its limitations, the model provides a method 
through which asset freezing could be studied in future research. For instance, the model does not include competition among firms, but the approach developed here could be extended to study this type of rivalry.

\subsection{Model assumptions}

The model considers the case of a firm that has to decide on two political instruments (campaign contributions and asset freezing), in different possible environments (parameters), potentially facing different politicians in the relevant short-term horizon (incumbent government in office and potential entrant).

Each one of the two next possible governments maximizes utility attached to votes, reached both by long-term efficient policies and short-term monetary and non-monetary resources available to improve the way these politicians and their policies are perceived by voters.

The timing of the model is the following: nature moves and chooses the environment, including the probability - perceived by the individual firms - that the incumbent politicians remain in office in the short-term (with different probabilities off-election times and at-election times); the firm then chooses its contributions to the two potential government officials (incumbent and entrant), as a contract in exchange for a specific regulation favoring its private performance/ market profit; based on those contracts, the winning candidate implements the short-term regulatory agreement struck with the contributing firm.

The solution is found backwards. Conditional on the information disclosed by nature $(N)$, the firm $(F)$ maximizes its expected profit anticipating the optimal reaction of the two possible political candidates $(G)$ who will be in office in the near future, where the transaction can be enforced based on reputation. In other words, the politicians' problems are solved first, and their reaction functions are introduced into the firm's maximization problem.

The policy space is the "level of regulation," ordered with increasing value when it moves to benefit the lobbying firm, as shown in Figure 2. This figure considers only one possible type of government official $G$, choosing between the spontaneous/unbiased policy - the one he considers to be first-best, $R^{F B}$ - and the policy that maximizes the private profits reached by the lobbying firm, $R^{\max }$.

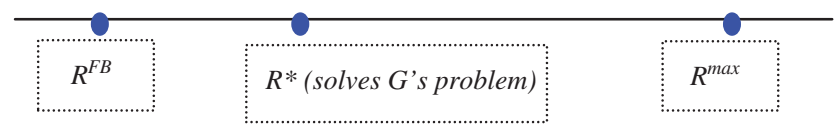

Figure 2 Policy space. 


\subsection{Utility functions}

The expected profit of the firm is denoted by $E(\pi)$ :

$$
E(\pi)=\phi \pi_{I}^{M}\left(R_{I}\right)+(1-\phi) \pi_{E}^{M}\left(R_{E}\right)-C\left(A F\left(R_{I}\right)\right)-S_{I}\left(R_{I}\right)-S_{E}\left(R_{E}\right),
$$

where

- $\phi$ is the probability that the incumbent official (I) remains in office during the next period (say, 2-4 years); while this probability is endogenous for politicians when they plan their actions, the firm takes this probability as given by nature (exogenous regarding the amount of funds or support it offers to either government official),

- $\pi^{M}$ denotes the market profit (gross of nonmarket expenditures), which depends on regulation $R$ ( $R_{I}$ and $R_{E}$, respectively),

- $A F\left(R_{I}\right)$ is the (economic) amount of assets frozen "transferred to" (i.e., invested to please) the incumbent politician in exchange for regulation $R_{l}$,

- $C\left(A F\left(R_{I}\right)\right)$ denotes the cost incurred by the firm to generate a transfer $A F\left(R_{I}\right)$ of frozen assets, and

- $S_{I}\left(R_{I}\right)$ and $S_{E}\left(R_{E}\right)$ are the (monetary) campaign contributions to the incumbent and the entrant in exchange for policies $R_{I}$ and $R_{E}$, respectively.

We adopt a specific market profit function, given by

$$
\pi_{i}^{M}\left(R_{i}\right)=-z \times\left(R_{i}-R^{\max }\right)^{2},
$$

for $i=I, E$, where $z$ denotes the size of the firm (reaching higher gains when the regulation approaches the most beneficial one, defined as $R^{\max }$ ). We assume linear support contracts, so that

$$
\begin{aligned}
& A F\left(R_{I}\right)=A F \times\left(R_{I}-R_{I}^{F B}\right), \\
& S_{I}\left(R_{I}\right)=S_{I} \times\left(R_{I}-R_{I}^{F B}\right),
\end{aligned}
$$

and

$$
S_{E}\left(R_{E}\right)=S_{E} \times\left(R_{E}-R_{E}^{F B}\right),
$$

where $R_{i}^{F B}$ represents the first-best policy for long-term efficiency as seen by government official $i=I, E$. This means that the firm offers marginal supports $A F, S_{I}$ 
and $S_{E}$ for policies deviating from those that would (spontaneously) be adopted without such intervention. ${ }^{5}$

Regarding the function $C\left(A F\left(R_{I}\right)\right)$, we assume that there is a higher cost incurred by freezing assets when the firm's assets are less flexible [a multiplying parameter $D(\geq 1)$ captures this effect], and that frozen assets involve a fixed transaction cost (because agreeing and measuring the contribution is more difficult), which is diluted as the level of the non-monetary transference is higher. This second effect would be captured by assuming that the unit cost of frozen assets is initially high and decreases in $A F$. Yet, for algebra simplicity, we choose to represent the unit cost as decreasing in the size $(z)$ of the firm, which is positively correlated with all types of contributions, as its marginal benefit from policies closer to its preferred one increases in those cases. In short, a transfer $A F \times\left(R_{I}-R_{I}^{F B}\right)$ costs the firm $\left(\frac{D \times A F}{z}\right) \times\left(R_{I}-R_{I}^{F B}\right)$.

As for the two possible governments/politicians in office during the next short-term horizon, their utilities are generically defined as $U_{I}\left[X\left(R_{I}\right), A F\left(R_{I}\right), S_{I}\left(R_{I}\right)\right]$ for the incumbent and $U_{E}\left[X\left(R_{E}\right), S_{E}\left(R_{E}\right)\right]$ for the potential entrant, where $X\left(R_{i}\right)$ denotes efficiency motives and $A F(R)$ and $S(R)$ enter their utilities as instruments favoring their chances of winning the election. The incumbent government can receive frozen assets in exchange for less efficient regulation favoring the firm's interest, but the entrant cannot. ${ }^{6}$

Considering the linear incentives assumed [whereby $A F, S_{I}$ and $S_{E}$ denote marginal exchanges per unit of $R_{i}$ away from the first-best (i.e., closer to $R^{\max }$ )], we also adopt specific utility (or loss) functions for the two potential governments, given by

$$
U_{I}\left(X\left(R_{I}\right), A F, S_{I}\right)=-\alpha_{I} \times\left(R_{I}-R_{I}^{F B}\right)^{2}+\left(R_{I}-R_{I}^{F B}\right) \times\left(U^{A F} \times A F+U_{I}^{S} \times S_{I}\right),
$$

and

$$
U_{E}\left(X\left(R_{E}\right), S_{E}\right)=-\alpha_{E} \times\left(R_{E}-R_{E}^{F B}\right)^{2}+\left(R_{E}-R_{E}^{F B}\right) \times\left(U_{E}^{S} \times S_{E}\right),
$$

5 If other firms were lobbying in various ways, $R_{i}^{F B}$ would just represent the firm's expected policy when it offers no individual support to $G_{i}$.

6 We assume that negotiating to freeze assets with entrant politicians is impossible. We find this a natural assumption for two main reasons. First, incumbent politicians and firms have natural interactions overtime regarding the evolution of business, and these would help them overcome higher transaction costs attached to freezing assets. Second, altering economic decisions to favor entrants would entail some sort of sabotage to existing inputs (workforce in particular), which might be severely punished if detected, discouraging both firms and politicians in doing so. 
where $\alpha_{i}$ denotes the importance given to (efficient) regulation by each potential government official, $U^{A F}$ denotes the marginal utility (votes) received by the incumbent government official out of freezing assets, and $U_{i}^{S}$ denotes government $i$ 's marginal utility from campaign contribution $S_{i}$ (with $i=I, E$ ).

The sequence is described as follows:

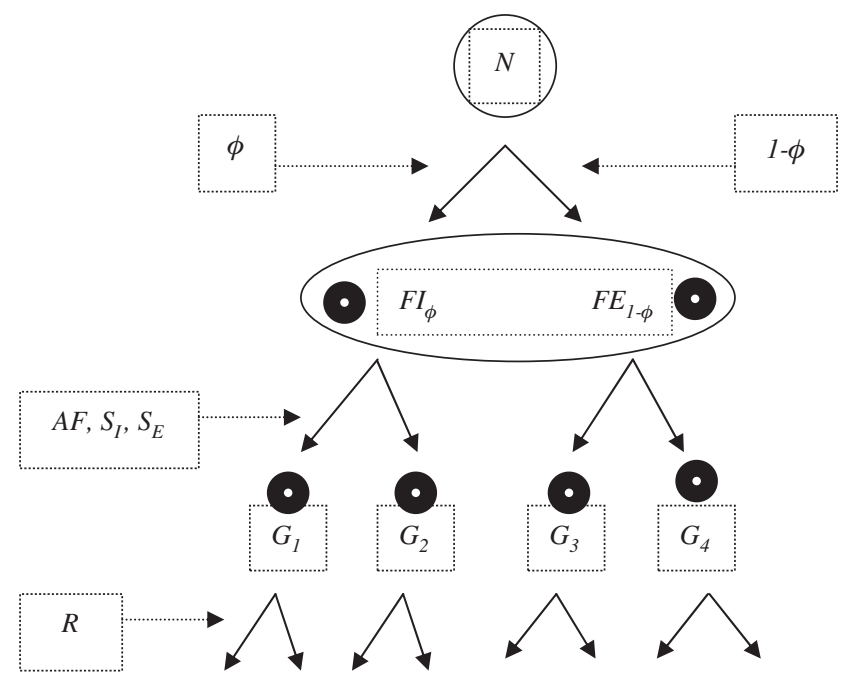

Nature chooses the government official for the following short-term period, but this choice is not observed by the firm, whose information set contains two decision nodes reached with probability $\phi$ (current officials will remain in office) and $1-\phi$ (challenger will win the election). The firm, then, has to choose all of its political offers/contracts $\left(A F, S_{I}\right.$ and $\left.S_{E}\right)$ with the two potential future government officials. Once these contracts are signed and the choice of nature is revealed, the government, knowing perfectly where it is at - so that each one of the decision nodes for both the incumbent and the entrant coincides with an information set -, chooses policy $R_{I}$ (last two nodes on the left) or $R_{E}$ (last two nodes on the right).

\section{Results}

As mentioned above, the solution is computed backwards. The problem for each possible government official, characterized by the first-order conditions of their respective maximization problems, is solved first: 


$$
R_{I}^{\star}=\frac{\left(U^{A F} \times A F+U_{I}^{S} \times S_{I}\right)}{2 \alpha_{I}}+R_{I}^{F B},
$$

and

$$
R_{E}^{\star}=\frac{U_{E}^{S} \times S_{E}}{2 \alpha_{E}}+R_{E}^{F B} .
$$

Second, the expected profit of the firm subject to these last two equations has to be maximized. The program is thus to choose $A F, S_{I}$ and $S_{E}$ in order to:

$$
\begin{aligned}
\max E(\pi)= & -\phi Z\left(R_{I}-R^{\max }\right)^{2}-(1-\phi) Z\left(R_{E}-R^{\max }\right)^{2} \\
& -\frac{\left(D^{\star} A F\right)}{z} \times\left(R_{I}-R_{I}^{F B}\right)-S_{I} \times\left(R_{I}-R_{I}^{F B}\right)-S_{E} \times\left(R_{E}-R_{E}^{F B}\right),
\end{aligned}
$$

subject to

$$
R_{I}^{\star}=\frac{\left(U^{A F} \times A F+U_{I}^{S} \times S_{I}\right)}{2 \alpha_{I}}+R_{I}^{F B},
$$

and

$$
R_{E}^{\star}=\frac{U_{E}^{S} \times S_{E}}{2 \alpha_{E}}+R_{E}^{F B} .
$$

The solution to this problem is characterized by three first-order conditions, with three unknowns $\left(A F^{\star}, S_{I}^{\star}\right.$ and $\left.S_{E}^{\star}\right)$ taking values depending on 11 parameters: $\phi, R^{\max }, R_{I}^{F B}, R_{E}^{F B}, \alpha_{I}, \alpha_{E}, D, U_{I}^{A F}, U_{I}^{S}, U_{E}^{S}$, and $Z$.

To facilitate computations, we assume that $R_{I}^{F B}=R_{E}^{F B}$ and $\alpha_{I}=\alpha_{E}$.

\subsection{Benchmark case: no frozen assets}

Imposing $A F=0$, the problem to be solved is the following: choose $S_{I}$ and $S_{E}$ to

$$
\begin{aligned}
\max E(\pi)= & -\phi Z\left(R_{I}-R^{\max }\right)^{2}-(1-\phi) Z\left(R_{E}-R^{\max }\right)^{2} \\
& -S_{I} \times\left(R_{I}-R^{F B}\right)-S_{E} \times\left(R_{E}-R^{F B}\right),
\end{aligned}
$$

subject to 


$$
R_{I}^{\star}=\frac{U_{I}^{S} \times S_{I}}{2 \alpha}+R^{F B},
$$

and

$$
R_{E}^{\star}=\frac{U_{E}^{S} \times S_{E}}{2 \alpha}+R^{F B} .
$$

The two first-order conditions for this problem are

$$
-\frac{\phi Z}{\alpha} U_{I}^{S}\left(R_{I}^{\star}-R^{\max }\right)-\left(R_{I}^{\star}-R^{F B}\right)-S_{I} \times \frac{U_{I}^{S}}{2 \alpha}=0,
$$

and

$$
-\frac{(1-\phi) Z}{\alpha} U_{E}^{S}\left(R_{E}^{\star}-R^{\max }\right)-\left(R_{E}^{\star}-R^{F B}\right)-S_{E} \times \frac{U_{E}^{S}}{2 \alpha}=0,
$$

which after rearranging terms result in

$$
S_{I}^{\star}=\frac{2 \alpha \phi z \times\left(R^{\max }-R^{F B}\right)}{2 \alpha+\phi z U_{I}^{S}},
$$

and

$$
S_{E}^{\star}=\frac{2 \alpha(1-\phi) z \times\left(R^{\max }-R^{F B}\right)}{2 \alpha+(1-\phi) z U_{E}^{S}} .
$$

Thus, we can check the symmetry of the solution. $S_{I}^{\star}$ and $S_{E}^{\star}$ respond positively to the size of the firm $(z)$, to the probability of each party winning $[\phi$ and $(1-\phi)$, respectively], to the importance attached to first-best policy by the government $(\alpha)$, and to the difference between the preferred policy and that considered to be the first-best by the politicians $\left(R^{\max }-R^{F B}\right)$. They respond negatively to governments preferring campaign contributions (i.e., those with higher utility from money $U_{I}^{S}$ and $U_{E}^{S}$ ).

\subsection{Equilibria in asset freezing}

Referring back to the original problem, where asset freezing is an available instrument, the solution to the firm's maximization problem is characterized by the following three first-order conditions: 


$$
\begin{gathered}
-\frac{\phi Z}{\alpha} U^{A F}\left(R_{I}^{\star}-R^{\max }\right)-\frac{D}{z} \times\left(R_{I}^{\star}-R^{F B}\right)-\left(\frac{D}{z} \times A F+S_{I}\right) \times \frac{U^{A F}}{2 \alpha}=0, \\
-\frac{\phi Z}{\alpha} U_{I}^{S}\left(R_{I}^{\star}-R^{\max }\right)-\left(R_{I}^{\star}-R^{F B}\right)-\left(\frac{D}{z} \times A F+S_{I}\right) \times \frac{U_{I}^{S}}{2 \alpha}=0, \\
-\frac{(1-\phi) Z}{\alpha} U_{E}^{S}\left(R_{E}^{\star}-R^{\max }\right)-\left(R_{E}^{\star}-R^{F B}\right)-S_{E} \times \frac{U_{E}^{S}}{2 \alpha}=0 .
\end{gathered}
$$

Since the first two equations can be rewritten as

$$
\frac{U^{A F}}{2 \alpha}\left\{\frac{2 \phi Z}{\alpha}\left(R_{I}^{\star}-R^{\max }\right)+\left(\frac{D}{z} \times A F+S_{I}\right)\right\}=-\frac{D}{z} \times\left(R_{I}^{\star}-R^{\max }\right),
$$

and

$$
\frac{U_{I}^{S}}{2 \alpha}\left\{\frac{2 \phi Z}{\alpha}\left(R_{I}^{\star}-R^{\max }\right)+\left(\frac{D}{z} \times A F+S_{I}\right)\right\}=-\left(R_{I}^{\star}-R^{\max }\right),
$$

they can hold together only if $\frac{U^{A F}}{U_{I}^{S}}=\frac{D}{z}$, which indicates that $A F^{\star}$ and $S_{I}^{\star}$ will be both positive (and the firm will be indifferent between them) only when the ratio between the marginal utilities generated for the current government by transfers $A F$ and $S_{I}$ is equal to the relative marginal cost of these instruments for the firm $(D / z)$.

We can then identify three different equilibria depending on these parameters:

(i) if $\frac{U^{A F}}{U_{I}^{S}}>\frac{D}{z}$, then $S_{I}^{\star}$ equals zero, and the solutions for $A F^{\star}$ and $S_{E}^{\star}$ are given by the first and third first-order conditions;

(ii) if $\frac{U^{A F}}{U_{I}^{S}}<\frac{D}{z}$, then $A F^{\star}$ equals zero, and the solutions for $S_{I}^{\star}$ and $S_{E}^{\star}$ are given by the second and third first-order conditions (as in the benchmark case when $A F$ is forced to be zero);

(iii) finally, if $\frac{U^{A F}}{U_{I}^{S}}=\frac{D}{z}$, then the levels of $A F^{\star}$ and $S_{I}^{\star}$ remain indeterminate, but the third first-order condition together with any of the other two provides the solution for $A F^{\star}+S_{I}^{\star}$. 
In case (i), imposing $S_{I}=0$, the solution to the maximization problem is given by:

$$
A F^{\star}=\frac{2 \alpha \phi z \times\left(R^{\max }-R^{F B}\right)}{2 \alpha \frac{D}{z}+\phi z U^{A F}},
$$

and

$$
S_{E}^{\star}=\frac{2 \alpha(1-\phi) z \times\left(R^{\max }-R^{F B}\right)}{2 \alpha+(1-\phi) z U_{E}^{S}} .
$$

Thus, while $S_{E}^{\star}$ remains as in the benchmark case, $A F^{\star}$ is fairly similar to the benchmark solution for $S_{I}^{\star}$, except that now its response to $z$ is larger (as it now also enters dividing in the denominator), and there is a negative response to D. Compared with campaign contributions to politicians in office, frozen assets increase faster when the firms become larger, and decrease when the firm's assets are less flexible, and thus the firm faces a higher cost for immobilizing inputs or choosing inputs of poor quality for political reasons.

More generally, looking at the three possible solutions together, the chances of finding the use of frozen assets decrease with $D$ and increase with $z$ :

(i) For less flexible assets, where the long-lasting effect of irreversible contributions for lobbying is higher, firms are less likely to use frozen assets as a lobbying instrument, whereas

(ii) Larger firms, which can dilute higher transaction costs as their contributions become larger, are also expected to freeze assets more frequently than small firms.

Regarding the relationship with size, the same pattern would be true in countries or institutional areas where (monetary) campaign contributions are limited and become binding restrictions for lobbying. Since the optimal levels of transfers of any kind, but particularly money, are higher when the firms become larger, such legal constraint would be more binding for larger firms because they use frozen assets more frequently. ${ }^{7}$

7 Notice that our model considers the problem faced by one firm, and thus cannot capture interactions between firms whereby they might coordinate contributions or compete for political favours. While this is a relevant limitation, and in particular we agree with one referee on the importance of capturing potential free-riding problems, we believe that such questions are equally relevant regarding monetary campaign contributions. Thus, sectors characterized by larger firms (and higher concentration ratios), and facing lower international competition (low contestability) would be in a better shape to avoid free-riding of individual firms on lobbying activities, both monetary campaign contributions and asset freezing ones. But, in any case, our model highlights the differential influence of firm size and sector regarding the latter - because of the higher transaction cost involved in measuring them and the inability to provide them to challenger politicians. 


\section{Conclusions}

This article sets out to provide a first and primary exploration of asset freezing as a corporate political resource, and how this concept could help explain the Tullock paradox. This paper provides a conceptual discussion of which economic assets could be frozen for political reasons, and puts the focus on two key dimensions: the political value and the flexibility of a firm's political asset. The article then develops a simple theoretical model looking at the trade-off between asset freezing and campaign contributions as political resources. In this model, firms as part of political transactions or lobbying efforts not only offer financial contributions to both incumbent and entrant politicians but also distort their productive decisions to generate political benefits to incumbents heading to an election. The decision to contribute with in kind or financial transfers emerges from an optimization process where each firm compares the marginal benefits and costs of both alternatives regarding their expected effect on policy.

The first main empirical implication of our model is that such non-financial contributions should be expected by large firms (the only ones which can reach a scale sufficient enough to overcome fixed transaction costs to detect and measure "in kind contributions"). The second implication is that since they are substitutes with financial contributions, but can only be offered to incumbent politicians, they should coexist with larger financial contributions for entrants than for incumbents once the likelihood of each party winning the election is controlled for. Regarding this second implication, large firms should tend to offer relatively higher financial contributions to political entrants than to incumbents vis-à-vis the corresponding contributions offered by smaller firms.

Our approach provides a new explanation for the famous Tullock paradox. We show that campaign contributions are not necessarily an efficient way for firms to influence policy-making, even in an environment where these firms can do so with no restrictions. In certain situations, asset freezing - adopting costly business decisions benefiting incumbent politicians towards an election - can be a more efficient strategic option. Consider for instance employment decisions by firms of various sizes and belonging to different sectors. Larger firms in sectors with lower incidence of labor costs - who thus presumably are more capable of absorbing the fixed transaction cost of subtle in kind contributions - should create more net jobs prior to political elections, vis-à-vis smaller firms in sectors with high labor costs. This could be tested empirically in future research.

Note that this approach is also a new way to explore the idea proposed by Baron (2001), i.e., that firms strategically integrate market and nonmarket strategies (Bonardi 1999, 2004). Instead of just considering this question by studying the complementarity between firms' economic and political activities, we suggest here that similar assets might be the pillars of both activities. This creates clear opportunities 
for firms to differentiate in political environments, as different firms might freeze different types of assets. However, this also comes with constraints (Bonardi 2008). As indicated in our formal model, firms operating in more competitive or more dynamic industries will face a potentially significant cost when engaging in asset freezing, something that will limit the overall effectiveness of this type of political strategy.

The solution to the Tullock paradox proposed here is also compatible with other well-known tendencies of firm political behavior, such as the fact that governments tend to favor declining industries (Brainard and Verdier 1997) and "losers" over winners in general (Baldwin and Robert-Nicoud 2007). Our approach suggests that becoming a loser might be endogenous to the political game or, expressed differently, might be a choice by certain firms which focus on asset freezing as a way to influence public policy decisions.

Beyond contributing to the debate on political spending and contributing to the study of how firms develop political resources, our approach has important institutional and public policy implications. On the one hand, our framework suggests that democracy does not generate as much political competition as is often expected. Since asset freezing is asymmetric (it favors political incumbents vis-à-vis new entrants), jurisdictions that have large firms provide a very large advantage to incumbent politicians versus new entrants.

Second, our framework has implications for policy. It suggests that laws regulating lobbying and campaign contributions can only be partially efficient since there are other important vectors (probably more costly than campaign contributions) through which firms invest (Bonardi 2008). As these behaviors are not regulated, but encouraged by incumbent politicians, it is questionable whether lobbying regulation is really effective. These laws tend to constrain resources to which most interest groups have access, but leave untouched areas that favor certain firms and certain politicians over others.

Our paper has clear limitations, however, and should mostly be seen as a first step in exploring asset freezing as a corporate political resource. We hope to stimulate further research in a number of ways. First, we have left untouched the question of competitive interactions in the context of asset freezing. What happens when two firms - or more - compete to influence policy-making and use asset freezing? The answer to this question is far from obvious and certainly warrants more research. Second, we have compared here asset freezing with one type of corporate political behavior, i.e., campaign contribution. How does asset freezing interact with other political resources, such as strategic information or grass-root support? Last, it would be interesting to study asset freezing with a more complete model of government behavior, especially one in which reelection is endogenous. We hope to have stimulated enough interest in these questions, and leave them open for future research. 


\section{References}

Ansolabehere, S., J. M. Snyder, Jr. and M. Tripathi. 2002. "Are PAC Contributions and Lobbying Linked? New Evidence from the 1995 Lobby Disclosure Act.” Business and Politics 4 (2): 131-155.

Ansolabehere, S., J. M. de Figueiredo, and J. M. Snyder. 2003. "Why is There So Little Money in U.S. Politics?” Journal of Economic Perspectives 17: 105-130.

Baldwin, R. and F. Robert-Nicoud. 2007. "Entry and Asymmetric Lobbying: Why Governments Pick Losers?" Journal of the European Economic Association 5 (5): 1064-1093.

Barney, J. 1991. "Firm Resources and Sustained Competitive Advantage." Journal of Management 17: 99-120.

Baron, D. 1995. “Integrated strategy: Market and Political Components.” California Management Review 37: 47-65.

Baron, D. P. 2001. "Theories of Strategic Nonmarket Participation: Majority-Rule and Executive Institutions." Journal of Economics and Management Strategy 10 (1): 46-89.

Baron, D. 2003. Business and its Environment. Upper Saddle River, NJ: Prentice Hall.

Bertrand, M., F. Kramarz, A. Schoar, and D. Thesmar. 2006. "Politicians, Firms and the Business Cycle. Working Paper.

Bonardi, J. P. 1999. "Market and Nonmarket Strategies of a Former Monopoly During Deregulation: the British Telecom Case." Business and Politics 1 (2): 203-232.

Bonardi, J. P. 2004. "Global and Political Strategies in Deregulated Industries: The Asymmetric Behaviors of Former Monopolies." Strategic Management Journal 25: 101-120.

Bonardi, J. P. 2008. “The Internal Limits to Firms' Nonmarket Activities.” European Management Review 5: 165-174.

Bonardi, J. P. 2011. "Corporate Political Resources and the Resource-Based View of the Firm." Strategic Organization 9 (3): 247-255.

Bonardi, J. P., G. Holburn, and R. Vanden Bergh. 2006. Nonmarket Performance: Evidence from U.S. Electric Utilities. Academy of Management Journal 49 (6): 1209-1228.

Brainard, L. and T. Verdier. 1997. The Political Economy of Declining Industries: Senescent Industry Collapse Revisited. Journal of International Economics 42: 221-237.

Dahan, N. 2005a. "A Contribution to the Conceptualization of Political Resources Utilized in Corporate Political Action." Journal of Public Affairs 5: 43-55.

Dahan, N. 2005b. “Can There be a Resource-Based View of Politics? International Studies of Management and Organization 35 (2): 8-27.

Dari-Mattiacci, G. and F. Parisi. 2005. “Rents, Dissipation and Lost Treasure: Rethinking Tullock Paradox. Public Choice 124 (3, 4): 411-422.

Dean, T. J., and R. L. Brown. 1995. "Pollution Regulation as a Barrier to New Firms Entry: Initial Evidence and Implications for Future Research." Academy of Management Journal 38 (1): 288-303.

Faccio, M. 2006. “Politically Connected Firms.” American Economic Review 96: 369-386.

Ghemawat, P. and P. del Sol. 1998. “Commitment Versus Flexibility?" California Management Review 40 (4): 26-42.

Hazlett, T. W. and R. J. Michaels. 1993. "The Cost of Rent-Seeking: Evidence from Cellular Telephone License Lotteries.” Southern Economic Journal 59: 425-435.

Hillman, A. 2005. "Politicians on the Board of Directors: Do Connections Affect the Bottom Line?" Journal of Management. 31: 1-18. 
Hillman, A., A. Zardkoohi, and L. Bierman. 1999. “Corporate Political Strategies and Firm Performance: Indications of Firm-Specific Benefits from Personal Service in the U.S. Government." Strategic Management Journal 20: 67-81.

Holburn, G. and B. Zelner. 2010. "Political Capabilities, Policy Risk, and International Investment Strategy: Evidence from the Global Electric Power Generation Industry." Strategic Management Journal 31 (12): 1290-1315.

Keim, G. and B. Baysinger. 1988. "The Efficacy of Business Political Activity: Competitive Considerations in a Principal-Agent Context." Journal of Management 14 (2): 163-80.

Lawton, T. and T. Rajwani. 2011. "Designing Lobbying Capabilities: Managerial Choices in Unpredictable Environments.” European Business Review 23 (2): 167-189.

Milyo, J., D. Primo, and T. Groseclose. 2000. "Corporate PAC Campaign Contributions in Perspective." Business and Politics 2 (1): 75-88.

Oliver, C. and I. Holzinger. 2008. "The Effectiveness of Strategic Political Management: A Dynamic Capabilities Framework." Academy of Management Review 33 (2): 496-520.

Peteraf, M. 1993. "The Cornerstones of Competitive Advantage: A Resource-Based View." Strategic Management Journal 14 (3): 179-191.

Rehbein, K. and D. Schuler. Forthcoming. "Linking Corporate Community Programs and Political Strategies: A Resource-Based View." Business and Society.

Schuler, D. 1996. "Corporate Political Strategy and Foreign Competition: The Case of the Steel Industry." Academy of Management Journal 39: 720-737.

Stratmann, T. 1991. "What Do Campaign Contributions Buy? Deciphering Causal Effects of Money and Votes." Southern Economic Journal 57: 606-620.

Tullock, G. 1967. “The Welfare Cost of Tariffs, Monopolies and Theft.” Western Economic Journal 5: 224-232.

Tullock, G. 1972. “The Purchase of Politicians.” Western Economic Journal 10: 354-355.

Tullock, G. 1998. “Which Rectangle?” Public Choice 96: 405-410.

Yoffie D, and S. Bergenstein. 1985. "Creating Political Advantage: the Rise of the Political Entrepreneur." California Management Review 28: 124-139. 